\title{
Derecho de huelga y Constitución argentina de 1949: Las peticiones a la Convención Constituyente
}

\author{
Jorge Afarian \\ Universidad de Buenos Aires, Argentina \\ jorge.afarian@gmail.com \\ Sebastián Nabuel Pasarin \\ Universidad de Buenos Aires, Argentina \\ sebapasarin@gmail.com
}

Right to strike and the Argentine Constitution of 1949: The petitions to the Constituent Convention

\section{Resumen:}

La Asamblea Constituyente que sancionó la Constitución argentina de 1949 durante el gobierno peronista, tan efímera como inaugural de numerosos derechos económicos, sociales, culturales y especialmente laborales, vino a proponer un canal de diálogo hasta aquél momento muy novedoso, y que incluía la posibilidad de nuclear las propuestas y peticiones concretas provenientes de la sociedad civil de aquélla época. No nos detendremos a analizar los fundamentos y justificación histórico-política de la Carta Magna, sino que es nuestra intención dedicarnos a un derecho fundamental solicitado por numerosas peticiones, y que fue ignorado en igual medida tanto por la Asamblea como por el texto final de la Constitución: el derecho de huelga. Realizaremos un breve recorrido por el estado de la discusión en aquel momento, para luego detenernos en peticiones que a nuestro juicio son ilustrativas del clima social de la época respecto de este derecho.

Palabras Clave: Argentina, Constitución, 1949, Peticiones, Huelga.

\section{Abstract:}

The Constituent Assembly that sanctioned the Argentine Constitution of 1949 during the Peronist government, so ephemeral as it was inaugural of numerous economic, social, cultural and especially labor rights, came to propose a dialogue channel until that very novel moment, and that included the possibility of nuclear the concrete proposals and requests coming from the civil society of that time. We will not stop to analyze the foundations and historical-political justification of the Magna Carta, but it is our intention to dedicate ourselves to a fundamental right requested by numerous petitions, and that was ignored in equal measure both by the Assembly and by the final text of the Constitution: the right to strike. We will make a brief tour of the state of the discussion at that time, and then stop at requests that in our opinion are illustrative of the social climate of the time regarding this right.

KeYwords: Argentina, Constitution, 1949, Strike, Petitions.

\section{INTRODUCCIÓN ${ }^{1}$}

El $1^{\circ}$ de mayo de 1948, en ocasión de la inauguración del período legislativo en el Congreso, Perón comenzaba a anunciar la necesidad de reformar la Constitución Nacional para modernizarla y actualizarla. El 27 de agosto de 1948 se sancionó la ley 13.233 que declaraba la necesidad de la reforma "a los efectos de suprimir, modificar, agregar y corregir sus disposiciones, para la mejor defensa de los derechos del pueblo y del bienestar de la Nación". Luego de un intenso proceso de debate desarrollado entre el 21 de enero y el 16 de marzo de 1949 (del que solo participó, en parte, el radicalismo) la Convención Constituyente aprobó y publicó su texto final, entrando así en su corta vigencia, hasta el golpe que derrocó a Perón en 1955.

Los abordajes jurídicos sobre la Constitución argentina de 1949 oscilan entre dos miradas que, resumidamente, podríamos denominar "marginalista” y "partidista”. Así, por un lado, la mayor parte de la 
bibliografía jurídica se concentra en el debate acerca de la legitimidad-ilegitimidad de la ley de necesidad de reforma constitucional $n^{\circ} 13.233$, o en la cláusula de reelección presidencial, destacando su carácter “autoritario" y otorgándole un carácter marginal en la historia constitucional (Badeni, 2006; Bidart Campos, 1986; Ekmekdjian, 1992; Sagüés, 2012; Segovia, 2005).

Por otro lado, un conjunto importante de la literatura específica se concentra en los rasgos "nacionalistas" o "anti-imperialistas" de la reforma, además de sostener su legalidad y regulación de avanzada en términos de constitucionalismo latinoamericano y derechos sociales (Alvar, 1997; Azzali, 2014; Cholvis, 2013; Fara y Gerber, 2013; Ramella, 1960; Sampay, 1975; Terroba, 2010).

En este sentido, y tomando como base estas discusiones, la (no) inclusión del derecho de huelga también aparece como uno de los temas predilectos de los juristas, especialmente los laboralistas. Su análisis en el ámbito de la Convención Constituyente, la voz de los inspiradores de la reforma, las razones de su exclusión, constituyen los tópicos más recurrentes, aunque no los únicos.

Apoyados en una mirada revisionista propia de una gran parte de la historiografía argentina reciente (Palacio, 2013, 2018; Stagnaro, 2017), intentaremos hacer un aporte para enriquecer estos abordajes tradicionales, que intente hacerse otras preguntas soslayadas y supere cierto vacío empírico en la investigación sobre este proceso (Vita, 2019b). Particularmente, aportaremos el estudio de una fuente específica: las peticiones sobre el derecho de huelga a la Convención Constituyente de 1949.

La Convención Constituyente recibió, en el transcurso que duró su trabajo, e incluso antes, numerosas peticiones particulares y colectivas requiriendo la inclusión expresa de este derecho en el texto de la Constitución. Independientemente de los diversos matices de estas peticiones, su cuantía demuestra que fue una de las temáticas más importantes del proceso de discusión.

Ahora bien, ¿cuáles fueron esos colectivos y particulares que solicitaron su inclusión? ¿En qué términos? ¿Qué derechos la complementaban? El objetivo del presente trabajo es compartir el análisis de esta fuente, estimando que ello contribuirá a ampliar la caracterización del panorama político y social de la época y complementará las conocidas expresiones de los representantes del Estado, los convencionales y los juristas.

Vale señalar que este texto se inscribe en un serie de investigaciones vinculadas con el estudio de la producción normativa laboral, desde los tiempos de la Secretaría de Trabajo y Previsión, hasta el golpe de Estado de 1955 (Afarian \& Pasarín, 2017, 2018, 2019a, 2019b y 2019c; Pasarín, 2017), entendiendo que esta constituye un elemento ineludible a los fines de aportar a las caracterizaciones y grandes relatos de la etapa, como así también resulta necesario para comprender el sistema específico de regulaciones que el peronismo intentó establecer para las relaciones capital-trabajo.

\section{Movimiento obrero y Peronismo en ClaVe De Derechos}

La relación ente el movimiento obrero y el peronismo es un fenómeno que, precisamente por su riqueza y diversas aristas, es objeto de numerosos abordajes y múltiples reinterpretaciones por parte de la historia, la sociología, la economía y también el derecho. En este sentido, la particular vinculación del movimiento obrero con el Estado en el período peronista propone miradas y discusiones que distan mucho de finalizar.

Uno de los principales productos derivados de este fructuoso vínculo fue la efectivización de un conjunto de normas de derecho social, entre ellas un vasto corpus de regulaciones laborales y la Constitución que nos ocupa. Este proceso se encontró inscripto en la tendencia jurídica internacional de la época y la circulación de saberes en el contexto latinoamericano. ${ }^{2}$ No obstante, presenta rasgos específicos que merecen ser puntualizados y cuyas implicancias aún mantienen su vigencia hasta nuestros días.

Desde finales de 1943 hasta su asunción como Presidente en 1946, Perón fue el interlocutor estatal preferencial entre el movimiento obrero y el gobierno militar (Abós, 1986; Del Campo, 2012; Doyón, 2006; Luciani, 2014) pactando con la dirección sindical distintos tipos de prerrogativas de las que resulta una compleja trama de derechos. Los estatutos profesionales, acuerdos colectivos, jubilaciones y pensiones, sueldo 
anual complementario, vacaciones, vivienda, mutualidad, organización sindical, seguros, jornada de trabajo, constituyen los nudos principales de este modelo.

El triunfo electoral de Perón "legalizará" este conjunto de decretos-leyes con la sanción de la ley 12.921 del 31 de diciembre de 1946, dando un "reaseguro institucional" al movimiento obrero de sus conquistas y, al mismo tiempo, corriendo el horizonte de las luchas de la etapa. ${ }^{3}$

Sumado a ello, también en este período se reglamenta la Justicia del Trabajo, tanto provincial (Bacolla, 2019; Gutiérrez, 2019; Kindgard, 2019; Mellado, 2019; Solís Carnícer, 2019; Stagnaro, 2017) como nacional (Palacio, 2018). Ésta vino a mediar en los conflictos de derecho e intereses entre capital y trabajo, con el objetivo de aplacar las disputas que pudieran suscitarse entre empleadores y trabajadores, en una época de constante crecimiento económico e industrial, junto con un acelerado desarrollo del sindicalismo.

Sobre la base de este marco legal específico se ubica el hito más importante del peronismo en materia normativa: la Constitución de $1949 .{ }^{4}$ Su sanción viene a cerrar una etapa altamente prolífera en lo que respecta a la producción de normas específicamente vinculadas con el derecho del trabajo y de la seguridad social, al elevar a la máxima jerarquía jurídica numerosos derechos sociales. ${ }^{5}$

En efecto, en el capítulo III de la Primera Parte (correspondiente a los principios fundamentales) del texto constitucional, se enuncian el derecho a trabajar, a una retribución justa, a la capacitación profesional, a las condiciones dignas de trabajo, a la preservación de la salud, al bienestar, a la seguridad social, a la protección de la familia, al mejoramiento económico y a la defensa de los intereses profesionales. Este último incluía el derecho a la libre agremiación y a la participación en "otras actividades lícitas tendientes a la defensa de los intereses profesionales”, dentro de las cuales podría inferirse el derecho a huelga (Sampay, 1975).

Esta somera contextualización resulta necesaria para presentar y describir la fuente en su contexto ya que las peticiones colectivas e individuales a la Asamblea Constituyente de 1949 provinieron fundamentalmente del movimiento obrero y sus organizaciones y fueron expresadas en clave de derechos. Sin embargo, en este texto queremos resaltar el debate sobre la ausencia del derecho a huelga en el texto constitucional aprobado, para lo cual es necesario repasar los términos de la discusión jurídica al respecto en la época.

\section{DEBATES EN TORNO A LA INCLUSIÓN EXPRESA DEL DERECHO DE HUELGA EN LA Constitución}

Mucho se especuló, en la doctrina jurídica laboralista, respecto de la falta de inclusión expresa del derecho de huelga en la Constitución, máxime cuando el modelo político-social peronista hacía de los derechos del trabajador uno de sus estandartes más importantes desde que Perón encabeza la Secretaría de Trabajo y Previsión hasta el "Decálogo de los Derechos del Trabajador" ya como presidente en 1947.

Desde un punto de vista "oficial", la tesis más difundida a los fines de dar respuesta respecto de la no inclusión del este derecho en el texto constitucional, proviene de la mano de Arturo Sampay, uno de los mayores promotores e ideólogos de la reforma, quien textualmente expresa:

El derecho de huelga es un derecho natural del hombre en el campo del trabajo como lo es el de resistencia a la opresión en
el campo político; pero si bien existe un derecho natural de huelga no puede haber un derecho positivo de la huelga, porque
-aunque esto haya sonado como un galimatías- es evidente que la huelga implica un rompimiento con el orden jurídico
establecido que, como tal, tiene la pretensión de ser un orden justo, y no olvidemos que exclusión del recurso de la fuerza es el
fin de toda organización jurídica. El derecho absoluto de huelga, por lo tanto, no puede ser consagrado en una Constitución,
a pesar de lo cual, dentro del derecho positivo argentino, se reglamente esa zona de guerra extra-jurídica que era la huelga
-como se hizo en Francia después de la ley de arbitraje y contratos colectivos de 1937 y en la Italia post-fascista- para que
pueda cumplirse en los casos en que los patronos no se avienen a satisfacer reclamaciones legitimas de los sindicatos obreros
(Diario de Sesiones de la Convención Nacional Constituyente, 1949, p. 275).

Aquí Sampay esboza una idea iusfilosófica específica, en comprobado diálogo con la conversación jurídica internacional de la época, en la que se ponían en debate las concepciones de autores como Hans Kelsen, Carl 
Schmitt y Hermann Heller, estudiados por él en su etapa formativa. En su concepción, la huelga es un derecho de resistencia natural, que no requiere ser explicitado en la normativa y menos en la Constitución, en tanto acompaña a la persona independientemente de su consagración en un texto legal (Sampay, 1996).

Asimismo, en este pensamiento aparece una noción teleológica de la Constitución: el sistema legal constitucional viene a excluir el imperio de la fuerza (huelga) y reemplazarlo por un orden justo (o pretendidamente justo). En consecuencia, cualquier ataque a ese orden será un rompimiento con este cometido, salvo que haya que resistir a lo no-justo. Allí entonces la huelga podría habilitarse, como el derecho humanitario o el derecho político de resistencia. No obsta a esta concepción -según la misma idea citadala reglamentación del derecho a nivel infra-constitucional para dar lugar a la huelga como respuesta ante el incumplimiento del empleador.

El tema presentó serios debates incluso al interior del peronismo, donde varios exponentes apoyaban otras concepciones. Una de las mayores posiciones antagónicas fue expresada por Pablo Ramella ${ }^{6}$, quien consideró que los argumentos de Sampay no resultaban convincentes, puesto que si el derecho de huelga era un derecho natural, por esa misma razón debía estar "positivizado" en la Constitución Nacional.

Partiendo de esta base, algunos años después, Ramella (1960) enriquece esta postura sosteniendo que, independientemente de que la huelga sea una manifestación de fuerza, aquello no le quita su carácter de jurídico. Aquél no es individual de cada trabajador, sino que es de ejercicio colectivo, y sólo pueden valerse de él los sindicatos, en defensa de los intereses del gremio. ${ }^{7}$

A pesar de que esta discusión no fue parte del debate en la Convención -en los términos contradictorios que aquí la presentamos- creemos que ambas posiciones resumen las divergencias existentes en la intelectual jurídica del peronismo respecto del derecho de reclamo colectivo por parte de los trabajadores y sus organizaciones: por un lado, la huelga como un "quiebre de institucionalidad", un derecho de resistencia, de ejercicio individual, que acompaña a cada persona en cualquier circunstancia y por ello no susceptible de ser "positivizado" en el texto constitucional (Sampay). Por el otro, el reconocimiento de la huelga como un daño o ejercicio de fuerza, pero de evidente legitimidad en tanto medio para obtener mejores condiciones laborales siempre que se ejerza en forma colectiva (Ramella).

Más allá de la discusión doctrinaria, la clase obrera como tal participó activamente de los debates a través de la gran cantidad de convencionales obreros y sindicalistas en las discusiones del proyecto de Constitución: Emilio Borlenghi, Hilario Salvo, Cecilio Conditi, Carlos Correa, José Espejo, Alejandro Giavarini, Rafael Giménez, Juan C. González, Oscar Vida Vidal resultan los más trascendentes.

Sin embargo, en sus intervenciones durante las sesiones de la Asamblea Constituyente, fueron escasas las defensas respecto de la inclusión del derecho de huelga, limitándose a sostener la postura oficial sobre la inclusión del "Decálogo de los Derechos del Trabajador" que diera a conocer Perón el 24 de febrero de 1947, o incluso expresando que la huelga iría en contra de los intereses de la clase obrera.

En este sentido, el convencional Hilario Salvo, dirigente de la Unión Obrera Metalúrgica, expresaba:

Decían también que en este proyecto concedían el derecho de huelga. Como dirigente obrero debo exponer por qué razón la causa peroniana no quiere el derecho de huelga. Si deseamos que en el futuro esta Nación sea socialmente justa, deben estar de acuerdo conmigo los señores convencionales en que no podemos, después de enunciar este propósito, hablar a renglón seguido del derecho de huelga que trae la anarquía y que significaría dudar de nuestra responsabilidad y de que en adelante nuestro país será socialmente justo (Diario de Sesiones de la Convención Nacional Constituyente, 1949, p. 486).

En el mismo sentido, el Secretario General de la CGT, José Espejo consideraba: "La posición de que los obreros, en sus luchas de reivindicación, deben colocarse en una actitud de intransigencia frente a los poderes del Estado es una posición rebelde y destructiva (...) El sindicalismo argentino, o el nuevo sindicalismo, como podríamos llamarlo, tiene su comienzo en Perón, y los obreros argentinos empezamos en ese instante a vivirlo, cuando él después de enunciar sus postulados sociales, se entregó a la tarea de practicarlos" (Diario de Sesiones de la Convención Nacional Constituyente, 1949, p. 487). 
Como se observa, los convencionales obreros se apoyan en la idea del peronismo como orden social intrínsecamente justo, priorizan su fidelidad al proyecto y resignan ciertas herramientas que podían interpretarse como derechos de corte absoluto. No están pensando en la realidad de las fábricas o lugares de trabajo, sino en un recurso eventual contra el gobierno.

A su vez en los años anteriores, principalmente el período desde 1946-1948, si bien comienza a evidenciarse un fuerte desarrollo económico y crecimiento del empleo, también asistimos a un período de alta conflictividad sindical y huelgas que "atentaban contra la productividad" (Campos, 2012; Doyón, 2006; Gaudio \& Pilone, 1983). Ante esta realidad, la posibilidad de consagrar a la huelga como un derecho constitucional de los trabajadores, sin discutir condiciones para su ejercicio, también podía envalentonar la "realidad de las fábricas" lo que podría considerarse uno de los motores para que la dirigencia sindical y política oficialista lo rechace.

De cualquier manera, es evidente que el tema se coló en la Convención, a pesar de que ninguno de los proyectos de texto considerados lo contenían. Por fuera del debate intelectual y la negativa de la dirección sindical en la Asamblea Constituyente, hallamos un tercer actor que explica por qué fue un tema imposible de ignorar para quienes hicieron uso de la palabra en el recinto. Este trabajo se centrará en ellos y ellas: los sujetos particulares y colectivos que peticionaron ante la Convención Constituyente reclamando la inclusión del derecho de huelga. ${ }^{8}$

\section{Las Peticiones a la Asamblea Constituyente de 1949}

Las peticiones a la Asamblea Constituyente se componen de 228 expedientes que documentan notas remitidas en su mayoría al presidente de la Convención, Domingo Mercante, entre enero y marzo de 1949, ingresadas de la misma manera en que lo eran todas las peticiones y solicitudes de "particulares" al Congreso Nacional. ${ }^{9}$

En este trabajo analizamos las peticiones individuales y colectivas a la Convención Constituyente, intentando rastrear qué ideas circulaban en la sociedad en general y el movimiento obrero en particular respecto al derecho de huelga. Creemos que el análisis de la fuente en cuestión resulta un valioso aporte a fin de caracterizar este panorama social.

Trabajamos doscientas catorce peticiones sobre temáticas sociales que están incluidas en el Archivo y Registro de Leyes del Senado de la Nación y se están organizadas en cinco cajas (números 3, 4, 5, 6y 11) y cuya variedad, como veremos, enriquece los enfoques teóricos respecto de la demanda de inclusión del derecho de huelga en la Constitución de 1949. Todas las peticiones fueron presentadas entre finales de 1948 y marzo de 1949, aún después de la sanción de su texto definitivo en el Congreso de la Nación. En concreto, del recorte realizado 85 peticiones planteaban expresamente la necesidad de incorporar el derecho a huelga en la nueva Constitución Nacional. 
Peticiones sobre derecho de huelga a la Convención Nacional Constituyente de 1949

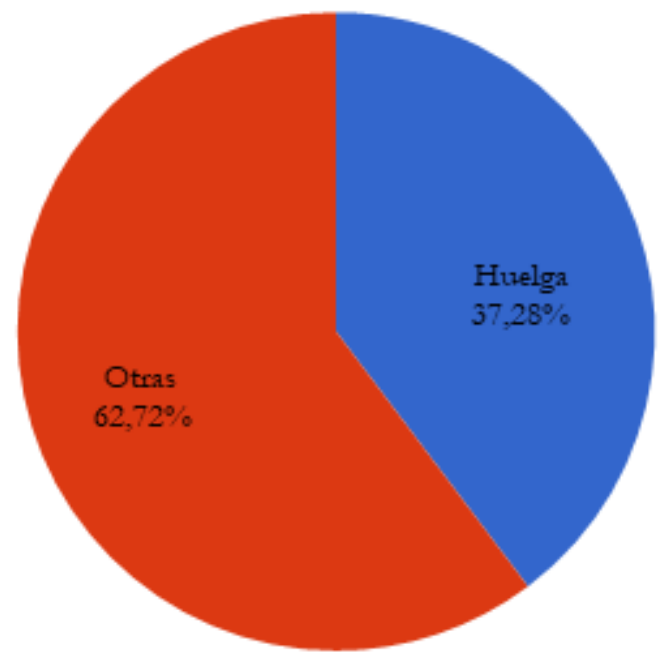

Fuente: Elaboración propia con base en el Archivo y Registro de Leyes del Senado de la Nación

En este sentido, hallamos tanto peticiones de particulares (obreros, profesores, abogados y otros profesionales), como colectivas, correspondientes a organizaciones de las más diversas orientaciones políticoideológicas: socialistas, comunistas, cooperativistas, peronistas y radicales, así como asociaciones de carácter empresarial, tanto industrial como rural. Por otra parte, la fuente nos ofrece la posibilidad de observar ciertos niveles de organización y dinámicas de funcionamiento de las entidades sindicales y la sociedad. En muchos casos las peticiones implicaron grandes esfuerzos de comunidades de vecinos y obreros plasmados en notas mecanografiadas, enviadas por correo con firma y membrete que atestiguan procesos internos de discusión y toma de decisiones.

En su mayoría, las peticiones que abordan el tema del derecho de huelga fueron realizadas por sindicatos, gremios, comisiones internas y trabajadores y trabajadoras. También participaron activamente grupos de vecinos o colectivos de variada composición, que compartían un vínculo territorial. ${ }^{10}$

A efectos pedagógicos creemos conveniente presentar una selección de las peticiones que pueden contribuir con la caracterización del horizonte de debate y concientización respecto del derecho de huelga, de acuerdo a los actores involucrados. En algunos hacemos transcripciones textuales de las peticiones, aún con sus faltas gramaticales y de ortografía, cuyo objetivo es la estricta fidelidad con el original. Para una mejor descripción, proponemos una clasificación de las peticiones en función de su emisor.

Aunque excede el objeto de este trabajo, vale aclarar que el pedido de inclusión del derecho a huelga, en general, viene acompañado de un cúmulo de peticiones relativas a eliminar el aparato legal de represión (Leyes de Residencia y de Defensa Social, eliminación del decreto-ley de Seguridad del Estado), modificar las cláusulas limitativas de participación de los extranjeros, participación en las ganancias, en la producción y la comercialización de bienes, la puesta en marcha del Instituto Nacional de Remuneraciones , la reforma agraria, entre muchas otras.

\section{Las Asociaciones Civiles y la aCADemia}

En el intento de rastrear la participación de la sociedad civil nos encontramos con diversas asociaciones que defendieron la inclusión de cláusulas constitucionales contemplativas de los intereses específicos de los colectivos que representaban. Varias estuvieron interesadas en la sanción expresa del derecho de huelga. 
Creada por un grupo de abogados defensores de obreros el 20 de diciembre de 1937 en el salón de actos del Diario "Crítica" y actualmente en funcionamiento, la Liga Argentina por los Derechos del Hombre emitió una escueta petición a la Comisión. En efecto, el 8 de marzo de 1949 se recibe una única hoja membretada con la razón social y la dirección de su primer local inaugurado en 1945 en la que se lee: "Los abajo firmantes consideran que los 'Derechos del Trabajador', cuyos diez artículos se incluirán en la nueva Constitución no tendrán ninguna validez si no se incluye el de huelga, base de todos los demás y corolario de todo movimiento obrero" (expediente $n^{\circ} 208$ ).

Los jóvenes, por su parte, se volcaron a la participación y emitieron a través de sus asociaciones, varias peticiones a la Convención. Como tema principal común se encontró la inclusión de los derechos de la juventud, principalmente el de trabajar y capacitarse. En contraste, prácticamente ninguna peticiona explícitamente a favor de la huelga. Solo en el caso del Centro de Estudiantes de Ingeniería de la Universidad Nacional de La Plata, referenciado políticamente con el radicalismo, observamos una mención explícita sobre el tema (expediente $\mathrm{n}^{\circ} 225$ ).

En las peticiones encabezadas por las asociaciones constituidas para la defensa de los intereses de la mujer, es reiterada la inclusión del derecho de huelga. Muchas adhirieron a la petición de la conocida Unión de Mujeres de la Argentina (UMA), fundada en Avellaneda en 1946 y de composición mayoritariamente obrera.

En esta presentación no solo se mencionó expresamente la necesidad de inclusión del derecho a huelga sino que se agregó un escueto, pero conceptualmente profundo comentario respecto de las razones que justificaban la necesidad de incorporar el derecho al texto constitucional: es "la única arma de los trabajadores contra la intransigencia patronal".

Por otro lado, en la misma petición se observa la denuncia sobre las facultades que el texto constitucional proyectado otorga al Poder Ejecutivo, a través de su artículo 86 inciso 19, esto es, la posibilidad de declarar el "estado de prevención y alarma". Para esta asociación, ese recurso implicaba una facultad discrecional y así lo expresaban: "Fácil es colegir que la más justa de las huelgas obreras podrá dar lugar a medidas de represión discrecionales".

Es difícil encontrar fuentes que den cuentas de la existencia de un debate en la academia sobre la Constitución, por lo que se suele afirmar que fue mayormente ignorado o negado, especialmente en los centros intelectuales hegemónicos dominados por el liberalismo y asociados con la oposición al peronismo como el Colegio de Abogados de Buenos Aires, cuya publicación oficial no registra en estas épocas artículos que tengan la Constitución de 1949 como tema.

En cuanto a la universidad, la Facultad de Derecho de la UBA, bajo el decanato de Lascano trató el tema encuestando a sus profesores y realizando una publicación del Instituto de Investigaciones de Derecho Político, Constitucional y de la Administración dirigido por Faustino Legón, ${ }^{11}$ profesor titular de Derecho Político.

Entre los expedientes analizados aparece la remisión de los debates que tuvieron lugar en el Instituto de Derecho Político Constitucional y Administrativo de la Universidad Nacional de La Plata, espejo de aquél que organizara la encuesta en la UBA y también dirigido por Faustino Legón (Barbarosch, 2016, p. 51) que en este caso presidió el debate.

El expediente permite ver otro procedimiento diferente al de la encuesta para discutir el tema de la reforma en una universidad tensionada por el peronismo. El Instituto analizó y emitió opinión al respecto de todos los artículos del proyecto de reforma y las actas de este debate fueron puestas en conocimiento de la Convención a través de la Secretaría de Educación de la Nación.

Entre los integrantes se encontraba Segundo V. Linares Quintana, Adolfo Korn Villafañe, Manuel María Diez y Juan F. Muñoz Drake. Lo interesante en este caso es que se atestiguó principalmente el disenso que existía entre ellos, primero respecto a la pertinencia de la reforma (principal argumento de la oposición política que sostenía la vigencia de la Constitución de 1853/60) y luego en los diferentes artículos en consideración. 
En particular, en lo que respecta a lo que aquí nos ocupa, las actas del debate dan cuenta de un planteo esquivo y crítico, apuntado principalmente al diseño del modelo sindical, considerando necesario que se incluya la libre asociación.

\section{Partidos Políticos}

Varios partidos políticos intervinieron en esta etapa de presentaciones. En relación con el derecho de huelga en particular, se observan principalmente peticiones del arco opositor al partido oficialista: el Partido Socialista, el Partido Comunista y la Unión Cívica Radical.

El núcleo "Unidad Socialista", dependiente del Partido Socialista (expediente $\mathrm{N}^{\circ} 42$, del $1^{\circ}$ de febrero de 1949), solicitó la expresa inclusión del derecho de sindicalización y el de huelga, con el fin de evitar su tergiversación por vía de la reglamentación o interpretación. También aludió a la inclusión de este derecho en numerosas constituciones modernas y la eliminación de la Ley de Residencia 4.144. ${ }^{12}$

Mención especial merece el análisis del derecho de huelga que realizó "Unidad Socialista" (no confundir con la anterior, que posee otro número de expediente) en su petición del 16 de febrero de 1949, archivada en el expediente $\mathrm{N}^{\circ} 130$. Allí solicitan la inclusión en forma taxativa del derecho de huelga en la Carta Magna y expresan su preocupación por el decreto de Seguridad del Estado ( $\mathrm{N}^{\circ} 536 \mathrm{del}$ año 1945$)$, que limita el derecho de huelga. Según denuncian, este instrumento había sido "legalizado" por la Corte Suprema de Justicia de la Nación.

Adicionalmente se aporta un estudio sobre la huelga como "hecho", a partir de numerosas experiencias en la Argentina, y cuyas principales motivaciones son cuestiones salariales. A través de la huelga, señalaron, "se readaptan" los jornales obreros. A su vez, indican la correlación entre las huelgas y los vaivenes económicos del país, el comercio exterior y el flujo migratorio: "cuando se viven tiempos de prosperidad aumenta el números de huelgas, disminuyendo éstas en las épocas de crisis”, por la incidencia de las crisis en el ahorro popular.

Luego buscaron desarticular lo que consideran un argumento a favor de los empleadores: el "abuso de la huelga”. Para ello señalaron que el conflicto gremial desembocaba en el terreno de la fuerza por exclusiva culpa patronal. Por ende, tal "abuso" era un argumento a favor de los empleadores. Desde este punto de vista, los trabajadores eran los más celosos guardianes de la tranquilidad en el trabajo, si ella resultaba compatible con su derecho a la vida. Esta cuestión -siempre según la opinión reseñada- se veía más nítidamente a medida que avanzaba la organización sindical y la legislación del trabajo, a través de la conciliación y el arbitraje.

Más adelante se refirieron a la "naturaleza" de la huelga remarcando que si bien es un recurso de fuerza, respondía también a una situación de fuerza. Aunque se produjera por motivos puramente gremiales, poseía siempre trascendencia política, ya que en sus proyecciones planteaba los elementos de la legislación obrera y era una de las bases del "Nuevo Derecho". ${ }^{13}$

La huelga era caracterizada entonces como la disputa por diferencias de intereses entre obreros y patrones. Cuando estas disputas no se lograban canalizar a través de vías conciliatorias, desembocaban en un conflicto que se caracterizaba por una paralización del trabajo. Por otro lado, la huelga no dependía exclusivamente de la voluntad obrera. Por el contrario las causas debían buscarse en la insatisfacción de legítimas demandas obreras por parte de los empleadores. Así, en los conflictos no sólo se ventilaban intereses contrapuestos, sino que también se debatían problemas de subsistencia, planteados partir de una inferioridad de condiciones.

Por último, expresaron que anular el derecho de huelga también implicaba anular la libertad sindical y la desaparición del sindicato obrero como tal. La represión de la huelga a través de la Ley de Residencia y la Ley de Defensa Social ( $N^{\circ} 7029$, de 1910), mereció las más fervientes protestas por parte de los trabajadores y la opinión pública.

Consideraron al conflicto como de "alto valor social, profundo contenido civilizador y progresista y encomiable sentido ético y reparador". Si bien indican que tanto la legislación como la jurisprudencia ya se 
habían pronunciado a favor de la huelga, su petición resaltó y exigió concretamente la inclusión en la Carta Magna.

Por su parte, el Comité Central del Partido Comunista, mencionó en su petición la necesidad de constitucionalizar el derecho al trabajo, la prohibición de represalias de los patrones en razón de la actividad sindical o política, por sus ideas, nacionalidad o religión y el "derecho inalienable de huelga", sin la que todos los demás derechos del trabajador serían vanos. Además, solicitó la reforma agraria y la derogación de la Ley de Residencia 4.144.

Aludieron a la huelga como derecho "por encima" de todos los demás de carácter social y laboral, considerándolo como "única garantía de que los obreros podrán luchar contra la avaricia patronal, ya que la experiencia demuestra que los patrones desconocen constantemente los derechos del trabajador".

En lo que respecta al comunismo, debemos resaltar que algunas intervenciones partidarias fueron incoadas a través de peticiones de regionales, seccionales, comisiones internas y grupos de vecinos. Es el caso de la petición agrupada en el expediente $\mathrm{n}^{\circ} 23$, de finales de enero de 1949, suscripta por el Partido Comunista de Villa Ballester, la Comisión Interna de la Cristalería Di Benedetti de Wilde y el Sindicato de Obreros Estibadores de Carlos Pellegrini, F.C.C.A. que también solicitan someramente la inclusión del derecho de huelga, junto con la reforma agraria y la derogación de la Ley de Residencia 4.144.

En cuanto a las peticiones de los comités provinciales del Partido, fueron recibidas las de Catamarca (expediente $n^{\circ} 189$ ) y Santa Fe (expediente ${ }^{\circ} 111$ ) con fuerte presencia de las demandas particulares del agro.

Por su parte, la Unión Cívica Radical intervino a través de una extensa carta suscripta por los convencionales constituyentes Víctor Alcorta, Luis López Carranza y Carlos Fernández Jensen, de activa participación en las sesiones posteriores (expediente $n^{\circ} 171$ ).

La argumentación de los convencionales conjugó historia, filosofía y política en busca de sostener la defensa de la Constitución "histórica" de 1853. El texto puede fraccionarse en cuatro apartados: en primer lugar, el repaso y análisis filosófico político de sistemas de gobierno del mundo, con especial énfasis en la comparación entre nazismo y comunismo como sistemas totalitarios. En segundo lugar, el rescate de la idea democrática y humanista la que, según los autores, encontraba larga tradición en nuestro país, remontándose a la Revolución de Mayo. En este apartado se sostuvo la preferencia por un sistema político liberal donde el individuo juegue un rol central.

En una tercera aparece la crítica al peronismo y a su gobierno en contraposición con la reivindicación del gobierno radical en clave social. Por último, realizaron un breve análisis normativo del Proyecto de Constitución en el que se mencionó la omisión de la inclusión del derecho a huelga (págs. 52 y 60 ) y la verticalidad que caracterizaba al sistema sindical argentino, la cual implicaba la vulneración de la idea de "libertad sindical".

Vale recordar que la postura sostenida por la UCR ante la Asamblea consistió en desestimar la reforma de la Constitución y finalizar las deliberaciones apelando a argumentos de fondo (vinculados con la inconveniencia de un nuevo texto constitucional) pero también de forma, al denunciar el apartamiento del mecanismo de reforma establecido por la Constitución de 1853.

\section{Centrales Obreras y Grupos de Vecinos y Obreros}

Podría pensarse en cierta abstención por parte del movimiento obrero peronista, motivada por razones de representación en la Asamblea Constituyente o su estrecha relación con el partido gobernante. La postura sostenida posteriormente por la conducción sindical en las sesiones pareciera reforzar la idea de la conformidad. Sin embargo, la participación de colectivos obreros vinculados con el peronismo fue importante. También la de aquellos colectivos que mantenían tensiones u oposiciones directas con el partido de gobierno. 
Muchas se expresaron a través de su pertenencia territorial. También, hubo presencia de como comisiones internas, pequeños grupos y establecimientos o fábricas.

En efecto, podemos mencionar la petición de la "Clase Obrera en General de Hernando" (Provincia de Córdoba) -así identificados- que solicitó la inclusión derecho de huelga, entendido éste como "mejora” para el movimiento obrero. En aquella sintonía, los Vecinos de San Fernando también solicitaron el derecho de huelga, y la derogación de la Ley 4.144. En similares términos se formulan los reclamos de los "Vecinos de Villa del Pilar" (Formosa), en una petición del 14 de enero de 1949 y los "Vecinos de Comodoro Rivadavia", en una petición del 31 de enero de 1949

Por otro lado, los “Obreros y Vecinos de La Calera, La Calera Central y Dumesnil, Córdoba”, solicitaron la inclusión de la huelga en el "Decálogo de los Derechos del Trabajador", y coincidieron con los pedidos de reforma agraria "amplia". Expresamente plantearon: "la tierra a quienes la trabajan, campesinos pobres, obreros agrícolas". Solicitaron la nacionalización forzosa de extranjeros, porque de lo contrario ello atentaría contra la unidad nacional, señalando como una de las medidas para lograrlo la derogación de la Ley 4.144, impulsada por gobiernos oligárquicos y dictatoriales.

Los “Obreros y Vecinos del Barrio Yofré (Córdoba)", también solicitaron la inclusión de derecho de huelga, "como arma fundamental para la defensa de las conquistas obreras". En similares términos, los "Vecinos y Agricultores de la ciudad de Tres Arroyos" solicitaron la inclusión en tanto "derecho de los explotados". En igual sentido, los "Vecinos de Pedro Molina" (Guaymallén, Mendoza), y los "Obreros de la Construcción y Vecinos de Rio Cuarto" (febrero de 1949) plantean la necesidad de incluir el derecho de huelga en la Constitución. En similares términos se expresan los "Trabajadores textiles de Villa Progreso, Provincia de Buenos Aires" (expediente N 112-P, de febrero de 1949) y los "Obreros y Vecinos del Barrio Inglés (Córdoba)" (expediente 113-P, de febrero de 1949) que apoyan la inclusión de la huelga.

Respecto de las comisiones internas que reclaman la inclusión de la huelga, podemos señalar la del "Personal Obrero de Garbesi \& Cía (fábrica de sombreros)" (expediente $\mathrm{N}^{\circ}$ 101-P) y los "Obreros de la Usina Dock Sud-C.A.D.E." (expediente $\mathrm{N}^{\circ}$ 102-P). ), los "Obreros de la Fabrica Cerámica 'Palmar', Córdoba” (expediente $N^{\circ} 129$, del 15 de febrero de 1949), los “Obreros de la Construcción de Pergamino" (expediente $\mathrm{N}^{\circ} 51$, sin fecha).

Los "Obreros de la Construcción, Electricistas y Amiantistas que trabajan en la construcción de la fábrica de Penicilina” (Martínez, Provincia de Buenos Aires), bajo el expediente $N^{\circ}$ 99-P, entendieron la huelga como "último recurso empleado por la clase obrera en la lucha por mejor condiciones de vida, es la única arma a la que podríamos recurrir frente a la intransigencia y egoísmo de los capitalistas, sin el derecho de huelga estamos completamente desarmados, y todos los demás derechos enunciados en el proyecto oficial carecería de la garantía necesaria para hacerse respetar (...)"

Hubo también seccionales y regionales de diversos sindicatos que peticionaron. Algunas, como el caso de la CGT de La Pampa, estuvieron vinculadas con robustecer las intenciones partidarias. El 10 de marzo de 1949 el Secretario General de la CGT, José Espejo, remitió una nota en la aúna los pedidos contenidos en "varios telegramas" de "los sindicatos obreros del territorio de La Pampa". Allí, según la propia nota de remisión, "el clamor de la población laboriosa del Territorio de La Pampa, manifestado a través de sus organizaciones sindicales representativas" ${ }^{14}$ se centra en torno al pedido de reelección presidencial y la provincialización de La Pampa (expediente ${ }^{\circ} 223$ ).

El Sindicato de Obreros y Empleados de YPF (Subseccional de Comodoro Rivadavia), de orientación peronista, requirió la incorporación del derecho de huelga en la Constitución como medio para "vigorizar el movimiento revolucionario del General Perón”. En términos similares, el Sindicato Textil, adherido a la Federación Obrera Textil Argentina, solicitó la inclusión del derecho de huelga, que definían como un "derecho inalienable" y legítimo. A su vez, consideraron que "es un derecho al cual, frente a cualquier alternativa, nunca renunciaremos". También el Sindicato de Obreros de la Construcción de Comodoro 
Rivadavia y el Sindicato de Obreros Estibadores de Carlos Pellegrini (F.C.C.A), en peticiones de finales de enero de 1949, solicitaron la inclusión del derecho de huelga.

La Federación Argentina de Agentes Comerciales (expediente $N^{\circ} 29$, del 31 de enero de 1949), expresó que si bien ellos habían sido partidarios de la conciliación y el arbitraje como medio para dilucidar conflictos entre trabajadores y empleadores, puesto que las medias de fuerza perjudicaban no sólo al capital y al trabajo sino a toda la sociedad, estimaron que muchas veces, "frente a la tozudez, la incomprensión y la avaricia patronal no queda para organización sindical otro recurso que la huelga, instrumento de defensa de los intereses de los trabajadores".

A su vez, reclamaron su inclusión en forma precisa, la que servirá como "garantía gremial" ante futuros gobiernos totalitarios y pro-capitalistas, los que considerarían a la huelga como un delito. Se apoyan en la tendencia internacional de inclusión del derecho de huelga en las constituciones latinoamericanas. ${ }^{15}$

La Unión Ferroviaria, en una petición de febrero de 1949, también consideró la huelga como "derecho irrenunciable que valora socialmente la función social de la clase trabajadora en el progreso del país, garantía legal al que sólo se oponen las oligarquías e imperialismos, como quedó demostrado en las sesiones de las Naciones Unidas en la que nuestro Canciller apoyó el derecho de huelga".

Observamos acumuladas en la caja n ${ }^{\circ} 4$ numerosas peticiones de seccionales del Sindicato "La Fraternidad". La Seccional de Bustos, Córdoba (expediente $\mathrm{N}^{\circ} 85$, del 9 de febrero de 1949), aludió a la huelga como "principio" y exigió su inclusión expresa en el texto de la Constitución, a la vez que reclamó por la reforma agraria y eliminación de la Ley 4.144. Las Seccionales de Victoria (vapor y diesel, F.C. Mitre), bajo el expediente 104-P, de febrero de 1949 y de Casilda, expediente 138-P, también incluyeron, entre otras, estas tres demandas.

Otra de las Seccionales de "La Fraternidad" (Alta Córdoba), bajo el expediente N 90-P, de febrero de 1949, exigió la inclusión de la huelga dentro del "Decálogo de Derechos del Trabajador", considerando que "si bien la huelga no es la manera conveniente más conveniente al país para solucionar los pleitos entre el capital y el trabajo, en cambio, para los trabajadores significa un arma que, al igual que las fuerzas armadas de los pueblos, la empuñamos en última instancia cuando agotados los medios pacíficos de persuasión el capital se obstina en la negativa de solución".

A su vez, consideraron que la falta de inclusión de este derecho, los demás derechos constitucionales les podrían ser negados en el futuro y carecerían de la fuerza para defenderlos, puesto que serían letra muerta ante potenciales desconocimientos de futuros gobiernos.

El Congreso Regional de "La Fraternidad" del Ferrocarril Nacional General San Martín, en Sampacho, Córdoba también solicitó la inclusión en el "Decálogo" del derecho de huelga, "única arma específica que tiene la clase obrera para defender los demás derechos reconocidos en el proyecto originario del pública notoriedad".

El Sindicato Obrero de la Industria Láctea, expediente $N^{\circ} 122$ de febrero de 1949, entre otros derechos, solicitó el de huelga, "para asegurar a los desposeídos un arma que usado prudentemente, asegure en última instancia la conquista de sus más elementales reivindicaciones".

La Unión Obreros de la Construcción de la Ciudad de Mar del Plata, expediente $\mathrm{N}^{\circ} 124$ de febrero de 1949, expresó que "el afán de lucro hace perder el sentido patriótico y humanitario a los que tienen a los obreros bajo su explotación, es imprescindible legalizar constitucionalmente la única arma que los trabajadores tienen para defenderse de la avaricia patronal, el derecho a cruzarse de brazos cuando se hallen agotados todos los recursos pacíficos para obtener los que justicieramente se necesita”.

También en Mar del Plata, la Sociedad Obreros, Sastres, Costureros y Anexos, expediente $\mathrm{N}^{\circ} 125$, de febrero de 1949, solicitó el derecho de huelga, la reforma agraria y la supresión de todos los aparatos para reprimir el movimiento obrero, a partir de la derogación de la Ley 4.144.

Por último no queremos dejar de mencionar que se admitieron también las peticiones de obreros individuales. Esto contribuye a priori con una mirada democrática amplia del proceso de discusión 
constitucional. Encontramos archivada la petición de Eugenio Martínez, autodefinido como un obrero "peronista y argentino". El texto remitido, fechado el 27 de febrero de 1949, rogó a la Comisión la extirpación del comunismo "para salvar a la Patria de ideas extranjeras". Pedro Flores, otro ciudadano peticionante, también solicitó que no se mencione en ninguna parte de la Constitución al Partido Comunista, ni a "sus satélites".

\section{Palabras Finales}

La fuente que presentamos da cuenta de un alto nivel de interés, conciencia y consenso en el movimiento obrero respecto de la exigencia del derecho fundamental de huelga. En particular, la positivización de este derecho aparece como el principal reclamo de los colectivos de trabajadores. Comprueba así la fuerte pujanza del movimiento obrero organizado y de base.

Asimismo, el trabajo constituye un aporte tanto al estudio de la oposición al peronismo como al entendimiento de este como un movimiento con cierta heterogeneidad y tensiones a su interior, en la medida que se da cuenta de la existencia "por abajo" de planteos y limitaciones sobre el proceso constitucional y de diferencias entre la dirección sindical y las organizaciones de base: en contraste con la participación de la dirección sindical en las sesiones de la Convención Constituyente, un gran número de trabajadores/as se volcó a peticionar en pos de agregar al "Decálogo" otorgado por Perón, el negado derecho de huelga.

De esta manera se explica por qué la Convención Constituyente trató el derecho de huelga cuando, en rigor, no integraba ninguno de los proyectos en consideración. Es evidente que hubo necesidad de dar respuesta a una demanda que se coló, por iniciativa y fuerza de sus impulsores, en el recinto. Y, aunque la oposición política partidaria acompañó, en muchos casos, el pedido e instó a aquellos grupos que les respondían a realizarlo (fundamentalmente desde el Partido Socialista y el Partido Comunista) también encontramos que existió debate en otros ámbitos sociales, barriales, académicos, de carácter independiente e interpelados por motivaciones y particularidades que deben ser rastreadas en cada caso.

En lo que respecta a la conceptualización de la huelga como derecho, el contenido de las propias peticiones nos habla la importancia otorgada a la herramienta: "derecho como garante de otros derechos". Las peticiones parecieran apoyar la visión de la huelga como un apartado significativo de la "agenda social", no solo durante el peronismo sino ya, para la época, desde hacía décadas.

En otra línea, la recepción de estas peticiones y su tratamiento implícito en las sesiones de la Convención invitan, cuanto menos, a pensar el vínculo entre la sociedad y el gobierno de manera diferente a la tradicionalmente caracterizada, en línea con algunos estudios que trabajan este vínculo desde diferentes perspectivas y actores sociales (Acha, 2004; Aboy, 2004; Barros, 2013; Pastoriza y Pedetta, 2009).

Las peticiones analizadas constituyen también un testimonio que enriquece o discute los relatos que se abocan al análisis del aspecto democrático/antidemocrático del peronismo, y la Constitución como mero artefacto para justificar la reelección presidencial indefinida.

Creemos que la participación de asociaciones, sindicatos, comisiones internas y agrupaciones vecinales, más allá del resultado final respecto al derecho bajo análisis, contribuye a otorgar legitimidad a la Constitución en su etapa constitutiva. Son mucho más populares las respuestas sobre la difusión y el conocimiento de la Constitución una vez sancionada. Sin embargo, no sucede lo mismo con la etapa que nos ocupa en este trabajo.

Del otro lado, y siguiendo a Vita (2019b), el Partido Comunista Argentino acusaba a Perón de elaborar un proyecto de reformas de espaldas al pueblo y por eso convocó a movilizarse y a organizar su presión sobre los asambleístas para obtener una reforma "popular y democrática y para asegurar especialmente el derecho de huelga".

Esto nos conduce al contexto de presentación de las peticiones: ¿Fue un llamado expreso por parte del gobierno peronista o constituyó una presentación espontánea por parte de los colectivos e individuales a la 
Asamblea Constituyente? Es decir, ¿fue de "arriba hacia abajo” o de "abajo hacia arriba”? La respuesta estas preguntas podría complejizar aún más las relaciones entre la comunidad y el Estado en aquella época, que como evidenciamos a lo largo de esta páginas buscaban un diálogo directo y fluido.

\section{ReFERENCIAS}

Abós, A. (1986). La columna vertebral. Sindicatos y peronismo. Buenos Aires: Hyspamérica.

Aboy, A. (2004). El "derecho a la vivienda". Opiniones y demandas sociales en el primer peronismo. En Desarrollo Económico, 44(174), 289-306.

Acha, O. (2004). Sociedad civil y sociedad política durante el primer peronismo. En Desarrollo Económico, 44(174), 199-230.

Alvar, M. (1997). La constitución revolucionaria que fue borrada de la historia. Buenos Aires: Apuntes de la F.J.A.

Afarian, J. \& Pasarín, S. (2017). Sindicalistas y Estado: un análisis comparativo de trayectorias e instituciones durante el peronismo clásico (1945-1955). En XVI Jornadas Interescuelas/Departamentos de Historia, Buenos Aires, Argentina: Universidad Nacional de Mar del Plata.

Afarian, J. \& Pasarín, S. (2018). El proyecto de ley sobre convenciones colectivas de trabajo de 1953 y la influencia gremial en su tratamiento parlamentario. Contexto y perspectivas. En VI Congreso de Estudios sobre el Peronismo, Buenos Aires, Argentina: Universidad Metropolitana para la Educación y el Trabajo.

Afarian, J. \& Pasarín, S. (2019a). Derecho de huelga y constitución de 1949: aporte de las peticiones a la Convención Constituyente. En VII Jornadas Nacionales de Historia Social, Córdoba: Centro de Estudios Históricos Prof. Carlos S. A. Segreti.

Afarian, J. \& Pasarín, S. (2019b). Las peticiones a la Convención Constituyente de 1949: saberes e identidad trabajadora en la provincia de Córdoba. En XIJornadas de Jóvenes Investigadores en Historia del Derecho. Buenos Aires: Museo Roca/Facultad de Derecho, UBA.

Afarian, J. \& Pasarín, S. (2019c, EN PRENSA). La ley sobre convenciones colectivas de trabajo de 1953 y la opinión sindical en su tratamiento parlamentario. Discusiones tempranas del "modelo sindical argentino". En Anuario del Instituto de Historia Argentina. Universidad Nacional de La Plata, 19(2), diciembre-junio.

Azzali, J. (2014). Constitución de 1949. Buenos Aires: Punto de Encuentro.

Bacolla, N. (2019). El mundo del trabajo mirado desde los estrados. Una aproximación a los espacios laborales y sus conflictos en provincia. Santa Fe a mediados del siglo XX. En VII Jornadas Nacionales de Historia Social. Córdoba: Centro de Estudios Históricos Prof. Carlos S. A. Segreti.

Badeni, G. (2006). Tratado de Derecho Constitucional. Buenos Aires: La Ley.

Barbarosch, E. (2016). La Encuesta del año 1949 formulada a los profesores de la Facultad de Derecho y Ciencias Sociales sobre la Reforma de la Constitución Nacional de 1853. El debate en la Convención Nacional Constituyente y el sustrato político ideológico de la reforma en las palabras de sus protagonistas. En Ortiz, T. (coord.). Hombres e ideas de la Facultad de Derecho. Ciudad Autónoma de Buenos Aires: Departamento de Publicaciones de la Facultad de Derecho y Ciencias Sociales de la Universidad de Buenos Aires.

Barros, M. (2013). Derechos que sujetan, sujetos de derecho bajo el primer peronismo. En XIV Jornadas Interescuelas/ Departamentos de Historia. Mendoza: Departamento de Historia de la Facultad de Filosofía y Letras. Universidad Nacional de Cuyo.

Benente, M. (2019) (comp.). La Constitución maldita. Estudios sobre la reforma de 1949. Buenos Aires: Edunpaz.

Bidart Campos, G. (1986). Derecho Constitucional. Buenos Aires: Ediar.

Campos, L. (2012). Estructura sindical, negociación colectiva y relaciones de fuerza. Un análisis de la trayectoria de las formas de organización y acción sindical en el largo plazo, Argentina 1945-2001. (Tesis de Doctorado, FLACSO). Recuperada de http://www.relats.org/documentos/HIST.Campos.pdf.

Cholvis, J. (2013). La Constitución y otros temas (dilemas del constitucionalismo argentino). Libro II: Constitución, economia y desarrollo. Córdoba: El Cid. 
Del Campo, H. (2012). Sindicalismo y peronismo: los comienzos de un vinculoperdurable. Buenos Aires: Siglo Veintiuno Editores.

Doyón, L. (2006). Perón y los trabajadores: los origenes del sindicalismo peronista. México, D.F.: Siglo Veintiuno Editores.

Ekmekdjian, M. A. (1992). Manual de la Constitución Argentina. Buenos Aires: Editorial DePalma.

Fara, L. \& Gerber, S. (2013). 1949. Una constitución para la patria justa, libre y soberana. Buenos Aires: Ediciones Piloto de Tormenta.

Gaudio, R. \& Pilone, J. (1983). El desarrollo de la negociación colectiva durante la etapa de modernización industrial en la Argentina, 1935-1943. Desarrollo Económico, 23(90), 255-286.

Gutiérrez, F. (2019). Justicia laboral, experiencia obrera y disputas por derechos. Tucumán durante el primer peronismo. En VII Jornadas Nacionales de Historia Social, Córdoba, Argentina: Centro de Estudios Históricos Prof. Carlos S. A. Segreti.

Kindgard, A. (2019). Mundo del trabajo y prácticas contestatarias en clave local. La experiencia del peronismo. En VII Jornadas Nacionales de Historia Social, Córdoba, Argentina: Centro de Estudios Históricos Prof. Carlos S. A. Segreti.

Luciani, M.P. (2014). El Estado peronista frente a las negociaciones colectivas: de las nuevas herramientas institucionales a la legalización de las convenciones colectivas. Revista Nacional de la Facultad de Ciencias Sociales, 34(49), 1-15. Recuperado de http://www.revistas.una.ac.cr/index.php/abra/article/view/6246/6237.

Mellado, V. (2019). Los trabajadores detrás de los estrados. Usos y prácticas de la justicia laboral durante el peronismo en Mendoza, 1953-1955. En VII Jornadas Nacionales de Historia Social, Córdoba, Argentina: Centro de Estudios Históricos Prof. Carlos S. A. Segreti.

Palacio J.M. (2013). El peronismo y la invención de la justicia del trabajo en la Argentina. Revista Nuevo, Mundo Mundos Nuevos, Open Edition Journals. Recuperado de http://journals.openedition.org/nuevomundo/65765.

Palacio, J.M. (2018). La justicia peronista. La construcción de un nuevo orden legal en Argentina. Buenos Aires: Siglo Veintiuno Editores.

Pasarín, S. (2017). El decreto 33.302 de 1945: prototipo del derecho del trabajo en la Argentina. Actas de las $V$ Jornadas de Jóvenes investigadoras/es en derecho y ciencias sociales del Instituto de Investigaciones "Ambrosio L. Gioja, Argentina. Recuperado de https://jornadasdejovenesinvestigadorasesenderechoycienciasblog.wordpress. $\mathrm{com} /$

Pastoriza, E. \& Pedetta, M. (2009), “Lo que el pueblo necesita”. Turismo social y Peronismo. Argentina, 1945-1955. En Études caribéennes, 13-14. Recuperado de https://journals.openedition.org/etudescaribeennes/3767\#quotation

Quiroga, B. (2010). Entrevista a Pablo A. Ramella (1987).En AA.VV, Constitución del '49. Reflexiones a 60 años. Buenos Aires: Ediciones de la Jefatura de Gabinete de Ministros.

Ramella, P. (1960). Derecho Constitucional. Buenos Aires: Grafico Standard.

Sagüés, N. (2012). Manual de Derecho Constitucional. Buenos Aires: Astrea.

Sampay, A. (1975). Las constituciones de la Argentina entre 1810 y 1972. Buenos Aires: Eudeba.

Sampay, A. (1996). Introducción a la Teoría del Estado. Buenos Aires: Theoría.

Segovia, J.F. (2005). El peronismo y la constitución de 1949 en la crisis de legitimidad argentina. En Anales de la Academia Nacional de Ciencias Morales y Politicas. Recuperado de https://www.ancmyp.org.ar/user/FILES/S egovia.pdf

Solís Carnícer, M. (2019). Los trabajadores en litigio. Una aproximación al mundo del trabajo en Corrientes a mediados del siglo XX a partir de fuentes judiciales. En VII Jornadas Nacionales de Historia Social, Córdoba, Argentina: Centro de Estudios Históricos Prof. Carlos S. A. Segreti.

Stagnaro, A. (2017). Y nació un derecho. Los tribunales del trabajo en la provincia de Buenos Aires. Buenos Aires: Editorial Biblós.

Terroba, M. (2010). La Constitución Nacional de 1949. Una causa nacional. Rosario: Fundación Ross. 
Vita, L. (2014). La legitimidad del derecho y del Estado en el pensamiento jurídico de Weimar. Hans Kelsen, Carl Schmitt y Hermann Heller. Buenos Aires: Eudeba/Departamento de Publicaciones de la Facultad de Derecho de la Universidad de Buenos Aires, Buenos Aires.

Vita, L. (2018). Constitucionalismo social como democracia económica. Una relectura de la Constitución de Weimar a la luz del aporte de Hugo Sinzheimer. Historia Constitucional, 19, 565-591.

Vita, L. (2019a). La reforma negada: la interpretación de la doctrina constitucional argentina contemporánea sobre la Constitución de 1949. En Benente, M. (comp.). La Constitución maldita. Estudios sobre la reforma de 1949. Buenos Aires: Edunpaz.

Vita, L. (2019b, EN PRENSA). El pueblo a la Constitución. La reforma constitucional de 1949 a la luz de las peticiones a la asamblea constituyente. En Boletín de la Biblioteca del Congreso, $\mathrm{n}^{\circ} 132$. Buenos Aires: Biblioteca del Congreso de la Nación.

\section{FUENTES}

Congreso de la Nación Argentina (1949). Diario de Sesiones de la Convención Nacional Constituyente de 1949. Buenos Aires: Imprenta del Congreso de la Nación.

Senado de la Nación Argentina (1949). Convención Constituyente de 1949. Buenos Aires: Archivo y Registro de Leyes. Convención Constituyente de 1949, Peticiones, Cajas 3, 4, 5, 6 y 11, Archivo y Registro de Leyes del Senado de la Nación.

\section{Notas}

1 Este trabajo se realizó en el marco del Proyecto de Investigación UBACyT 20020170200111, "La reforma constitucional argentina de 1949: alcances del constitucionalismo social argentino en perspectiva transnacional" (Programación 2018), a cargo de la Profesora Leticia Vita. A ella agradecemos sus valiosas sugerencias y lecturas, así como a Tatiana Celestino e Ismael Pasquinelli por el análisis y sistematización de las peticiones sobre derecho de huelga.

2 Países como México (1917), Brasil (1937), Bolivia (1938), y Cuba (1940), ya habían sancionado Constituciones con contenido social. En Europa el constitucionalismo social tuvo como exponentes a la Constitución de Weimar (1919) y la Bolchevique (1918) cuyos debates influyeron en los procesos constituyentes argentinos y brasileros (Vita, 2018).

3 Este formato específico de regulación de las relaciones capital-trabajo se encuentra inmerso en el contexto de posguerra y viene a dar respuesta al temor a la radicalización de la clase obrera. Aún antes de la finalización de la Segunda Guerra Mundial, ésta fue una de las razones para la creación de la Secretaría de Trabajo y Previsión, como un modo de ordenar el plano de las relaciones laborales a los fines de evitar la amenaza "extranjera" comunista, socialista y anarquista, durante el conflicto bélico que se encontraba en su apogeo. Para lograr este objetivo era necesario, entre muchos aspectos analizables, contar con una única organización sindical que nucleara y representara a los trabajadores y una intervención eficiente en los conflictos de clase por parte del Estado.

4 Para un análisis jurídico desde numerosos puntos de vista, ver Benente, 2019.

5 Luego de la sanción de la Constitución observamos un congelamiento en términos de producción de legislación del trabajo y de la seguridad social, apenas modificada por la sanción de la ley 14.250 sobre convenciones colectivas del trabajo en 1953 analizada en Afarian y Pasarín (2018).

6 Convencional constituyente por la provincia de San Juan durante el debate constitucional de 1949.

7 Ramella consideraba que la huelga podría ser ejercida una vez agotados los recursos "pacíficos" de reclamo, a través del diálogo con los empleadores, la conciliación, el arbitraje, entre otros. Además, no podían afectar los servicios públicos, puesto que el interés general de la sociedad prevalecería por sobre los del gremio o sindicato convocante de la medida de fuerza. Ver Quiroga (2010).

8 La oposición encabezada por la Unión Cívica Radical expresó conocidas defensas sobre la inclusión del derecho a huelga a través de sus convencionales. De igual manera lo hicieron muchos otros partidos que no participaron de las deliberaciones. Algunas posturas son reseñadas a continuación en este trabajo, en el marco de las peticiones a la Convención.

9 La descripción específica del acervo documental fue realizada por Vita, 2019b. 
10 Resultó común encontrarse con las denominaciones "Vecinos y Trabajadores", acompañada por la ciudad y el territorio que comúnmente habitaban (v.g. "Vecinos del barrio Alberdi Córdoba" o "Vecinos, obreros, empleados y comerciantes del barrio 12 de octubre (Olivos. Prov. de Bs. As.)".

11 Una descripción y análisis de este proceso puede leerse en Barbarosch, 2016.

12 A lo largo de las peticiones, la expresa inclusión del derecho de huelga se complementa con la reforma agraria y la derogación de la Ley de Residencia 4.144, sancionada en el año 1902, y que intentaba el disciplinamiento de los representantes de la clase trabajadores en aquellos años, es decir, los anarquistas y socialistas de origen extranjero (especialmente España e Italia) cuyos métodos huelguísticos y manifestaciones desprestigiaban y complicaban la situación del gobierno conservador representado por el Partido Autonomista Nacional. Estas medidas, consideramos, también venían a establecer un coto a las huelgas, deteniendo y deportando representantes obreros hacia sus países de origen, motivados en el desequilibrio del orden público general y la paz social.

13 Concepto popularizado por Alfredo Palacios en el libro homónimo de 1920, para argumentar a favor de la sanción de derechos sociales.

14 Lleva la adhesión de la Delegación Regional de Santa Rosa, el Sindicato de Reseros Estibadores y Rurales de Santa Rosa, Sindicato de Obreros Panaderos y Afines de Santa Rosa, Sindicato de Obreros de la Construcción de Santa Rosa, Centro de Empleados de Comercio de Santa Rosa, Unión Obrera Metalúrgica de Villa del Busto (Santa Rosa), Sindicato de Obreros Estibadores y Oficios Varios de Jacinto, Sindicato de Obreros de Oficios Varios de Salinas Grandes, Eduardo Castex, Alpachiri, Winifreda, Macachín y Conhello, Sindicato de Obreros de Miguel Cané y Sindicato de Trabajadores de Parera.

15 De acuerdo a la petición, las Constituciones boliviana, brasilera, colombiana, costarricense, cubana, ecuatoriana, salvadoreña, guatemalteca, mexicana, panameña, uruguaya y venezolana, habían incluido el principio de derecho de huelga, lo que es interesante en términos de circulación de ideas sobre constitucionalismo social y acceso a derechos sociales por parte de los países latinoamericanos. 